\title{
Editorial
}

\section{The sounds of silence}

One aspect of the international political policy known as détente has been an attempt to create and improve communication on scientific matters between East and West. According to some papers published in the previous volume of this fournal ${ }^{1}$, the pressure towards improved communication can obscure a frank discussion of certain ethical issues in medicine. If this is so, then more direct discussion of the meaning and nature of medical ethics seems highly desirable. Yet the task is a daunting one. Firstly, medical ethics in the West, although avowedly secular, has its roots in values derived from, and to some extent still nourished by, the Judaeo-Christian tradition, whilst no such religious grounding can be acknowledged in states officially opposed to religion. Secondly, the highly individualistic character of Western ethical principles appears to be in direct conflict with the stress on collective responsibility and on the over-riding authority of the state within Communist countries. Perhaps some of these differences are more apparent than real, but clearly a great amount of quite basic discussion about ethics is required before the appropriate lines of communication can be laid which will allow a dialogue on the issues of contemporary medical ethics.

In light of this, the papers in this issue by Popa and Hanganu of Romania and Milivoj Boranic of Yugoslavia, are of particular interest. Neither of these papers is in a style familiar to readers of this fournal. Most of our main articles are either casebased discussions of particular moral dilemmas in medicine or attempts to define the nature of medical ethics in the language of contemporary Anglo-American moral philosophy. Popa and Hanganu, on the other hand, in describing 'the faces of death' use a terminology which is strikingly metaphysical, though without specific religious reference. They end with the demand (which must seem startling to many clinicians) that the doctor caring for the dying must be 'a genuine philosopher in the strictest sense of the word'. Boranić's paper takes us into an equally difficult region. His 'silent information' is of course already a familiar concept in discussions of communication in medicine, though it would more commonly be described in this literature as 'non-verbal communication'. But the author takes us immediately into a set of philosophical problems concerned with subjectivism and verifiability. Just as Popa and Hanganu confront different understandings of the relation of man to the cosmos, so Boranić takes on no less a theme than the nature of truth.

Clearly it would be foolish to make sweeping generalisations on the basis of these two manuscripts, received in the relatively random manner in which a journal gains publishable copy. Yet, perhaps we may guess a little about the silence which goes unnoticed amid the clamour of political and semipolitical communications. In countries of every political persuasion the complex and ambiguous task of offering help to the suffering and dying is undertaken. To find out more how the moral and philosophical dimension of this helping is understood in Eastern European countries may mean listening carefully to the sounds in this silence. The voices we hear could help prevent a domination of medical ethics by one style of Western philosophy.

\section{More struck against than striking?}

Once more the British NHS has been subjected to a series of strikes-a term now superceded in mediaspeech by the high-sounding phrase industrial action'. Although we go to press three months ahead of publication, it seems highly likely that our Parliamentary column on the subject will still be topical. Most of Britain's hospitals have been badly affected by the suspension or interruption of catering, laundry and portering services and in parts of the country the ambulance service has been in a state of perpetual crisis. No doubt some news reports exaggerate the situation and many of us in Britain have been amused by letters from friends overseas who have been presented with a picture of a nation in a state of near collapse. Yet the situation for those who work in the Health Service and, even more, for those who need to use it, is undeniably serious. Perhaps the most unsettling aspect of the situation is the feeling that unrest about wages and working conditions is an unending spiral and that, as a consequence, no time of stability can be hoped for in the foreseeable future.

In this editorial column we have consistently opposed the idea that there can be any moral justification for strikes which hazard the safety of 